\title{
Clinical Spectrum of Acute Coronary Syndromes in Qatar
}

\author{
Manish Barman* and Bendaas Djamel
}

Department of Cardiology, Al Ahli Hospital, Doha, Qatar

\begin{abstract}
Objectives: The clinical profile among patients with acute coronary syndromes (ACS) is not well reported in Qatar. To determine the clinical characteristics and profile of patients having acute coronary syndromes presenting to a private tertiary hospital in Qatar.

Methods: Retrospective study conducted at a large tertiary center. Successive cases presenting with ACS to the coronary-care unit between January 2009 and December 2013 were included. Cases were grouped into ST-segment elevation myocardial infarction (STEMI) and non-ST-segment elevation myocardial infarction/unstable angina (NSTEMI/UA) for the purpose of analysis.

Results: Among 451 patients treated for ACS, 327(72.7\%) were males and 123(27.3\%) females. $36(8 \%)$ patients had STEMI, $269(59.8 \%)$ NSTEMI and 145(32.2\%) had unstable angina. $343(76.2 \%)$ had hypertension, $228(50.7 \%)$ had diabetes mellitus and $195(43.3 \%)$ were smokers. In $238(52.9 \%)$ patients the time of onset and reaching hospital was between 12 am to $6 \mathrm{am}$. More than $70 \%$ patients with ACS were in the age group of 41 to 60 years of age.

Conclusions: In a varied, multi ethnic and rapidly growing economy of Qatar the number of males suffering ACS far exceeds the females. A high prevalence of cardiovascular risk factors implies a continuing burden of cardiovascular morbidity and mortality. Improving the lifestyles of patients in the region will be crucial for improving long-term outcomes. Appropriate vision and emphasis is required for the management of cardiovascular risk factors and cardiovascular disease in this part of the world. The patient profile and characteristics including the risk profile helps us to understand the demographic variation and prevalence in our mix of multi ethnic, migrant and expat population utilizing the private healthcare sector services.
\end{abstract}

Keywords: Acute coronary syndrome; Cardiovascular disease burden; Qatar

\section{Introduction}

Coronary heart disease (CHD) is a major cause of death and disability in developed countries. Although CHD mortality rates have declined over the past four decades in the United States (and elsewhere), CHD remains responsible for about one-third of all deaths in individuals over age $35[1,2]$. It has been estimated that nearly onehalf of all middle-aged men and one-third of middle-aged women in the United States will develop some manifestation of CHD [3].

Globally coronary artery disease (CAD) is one of the leading causes of premature death and disability. In $2001 \mathrm{CAD}$ was responsible for $11.8 \%$ deaths in low and middle income countries and $17.3 \%$ in high income countries, accounting for more than 7 million deaths worldwide [4]. CAD is a chronic degenerative condition which may present via a wide spectrum of clinical syndromes including stable angina, acute coronary syndrome, heart failure, arrhythmia and death. As with CAD mortality, there are marked regional, socio-economic and ethnic variations in the incidence and prevalence of myocardial infarction (MI) [5].

Countries in Africa and the Middle East bear a heavy burden from cardiovascular disease. The prevalence of coronary heart disease is promoted in turn by a high prevalence of cardiovascular risk factors, particularly smoking, hypertension, dyslipidemia, diabetes, and sedentary lifestyles. Patients in Africa and the Middle East present with myocardial infarction at a younger age, on average, compared with patients elsewhere. The projected future burden of mortality from coronary heart disease in Africa and the Middle East is set to outstrip that observed in other geographical regions [6].

Coronary artery disease (CAD) is the leading cause of mortality and morbidity in the world and acute coronary syndromes (ACS), which encompass unstable angina (UA), non-ST-segment elevation myocardial infarction (NSTEMI) and ST-segment elevation myocardial infarction (STEMI), are the commonest causes of mortality in patients with CAD. With the introduction of a huge armamentarium of invasive and noninvasive therapeutic strategies, the mortality related to ACS has significantly reduced in the developed world over the past 20 years [7-12].

The prevalence of heart disease and premature morbidity and mortality from it are becoming apparent in various rapidly developing Middle Eastern countries such as Qatar [13].

The rising incidence of ACS in Qatar may be related to the changes in the lifestyle, the westernization of the food practices, the increasing prevalence of diabetes mellitus and probably genetic factors The health status of Qatar population differs from that of other developing states owing to its higher literacy rate, better distribution of its healthcare manpower within the country, and its better access to healthcare institutions. The clinical spectrum, the age and gender-specific differences in patients with ACS are not studied properly in Qatar

*Corresponding author: Dr. Manish Barman, Department of Cardiology Al Ahli Hospital, PO Box 6401, Doha, Qatar, Tel: +974-66936385; E-mail: drbarman@yahoo.com

Received February 27, 2014; Accepted March 18, 2014; Published March 24 2014

Citation: Barman M, Djamel B (2014) Clinical Spectrum of Acute Coronary Syndromes in Qatar. J Cardiovasc Dis Diagn 2: 149. doi:10.4172/23299517.1000149

Copyright: (c) 2014 Barman M, et al. This is an open-access article distributed under the terms of the Creative Commons Attribution License, which permits unrestricted use, distribution, and reproduction in any medium, provided the original author and source are credited. 
on a large- scale basis. In this background, this study was performed using the data extracted from the case records of patients treated with ACS between January 2009 to December 2013 in the Department of Cardiology of one of the biggest private referral centers and a tertiarycare hospital of Qatar.

\section{Patients and Methods}

Case records of all the cases admitted to the coronary care unit under the Department of Cardiology during these 5 years were searched. Those cases with proven non-cardiac chest pain and those who were discharged before completion of the treatment for any reasons were excluded from the analysis. The cases were grouped into two:

\section{1) Those presented with STEMI \&}

2) Those presented with NSTEMI/UA, for the purpose of analysis.

Cases of chest pain/discomfort with elevation of ST segment in electrocardiographic (ECG) leads/presumed new onset left bundle branch block in ECG were categorized as STEMI. Cases of angina at rest without ST segment elevation were categorized as NSTEMI if their cardiac Troponin I (Trop I) levels exceeded $0.04 \mathrm{ng} / \mathrm{ml}$ and as Unstable Angina if their Trop I levels were negative.

The baseline clinical characteristics analyzed in each group were the age, gender, hypertension (blood pressure $>140 / 90 \mathrm{mmHg}$ and/or those already taking treatment for hypertension), diabetes mellitus,dyslipidemia, smoking status, time of occurrence of the ACS, clinical course in the hospital and the mean duration of hospital stay. Region of myocardium involved (territory) was also noted.

\section{Statistical Methods}

Data were summarized as mean \pm Standard Deviation (SD) if they were normally distributed; otherwise, they were summarized as the median and interquartile range (IQR).

Differences between groups were assessed using Chi square or Fisher's exact tests for categorical variables, student's $t$ tests for continuous and normally distributed variables, and the Mann-Whitney $\mathrm{U}$ test for skewed variables. All analyses were considered significant at $\mathrm{P}<0.05$. The analysis was performed using IBM SPSS software

\section{Results}

574 patients were admitted to the coronary care unit during the study period with suspected ACS, of which, 451 cases qualified the inclusion criteria and their data was analyzed in the study. Gender and age distribution is represented through Pie charts. ACS cases with coexistent cardiovascular risk factors like diabetes mellitus, hypertension and smoking history were also analyzed. Among 450 patients treated for ACS, 327(72.7\%) were males and 123(27.3\%) females. 36(8\%) patients had STEMI, 269(59.8\%) NSTEMI and 145(32.2\%) had unstable angina. 343(76.2\%) had hypertension, 228(50.7\%) had diabetes mellitus and 195(43.3\%) were smokers. In 238(52.9\%) patients the time of onset and reaching hospital was between $12 \mathrm{am}$ to $6 \mathrm{am}$. More than $70 \%$ patients with ACS were in the age group of 41 to 60 years of age. Among the patients with ACS, the anterior region involvement was $64 \%$ and Inferior wall was involved in $35.6 \%$ the remaining were posterior/ lateral involvement. The mean duration of hospital stay in patients with STEMI was $3 \pm 1$ day (Table 1 and Figures 1-4).

\section{Conclusions}

The prevalence of coronary heart disease is high in countries of Middle East. A high prevalence of cardiovascular risk factors implies

\begin{tabular}{|c|c|c|c|c|c|c|c|c|c|c|c|c|}
\hline ACS & STEMI & NSTEMI & UA & HTN & DM & SM & REGION & $\begin{array}{l}\text { Age } \\
\text { Group }\end{array}$ & M & $F$ & CAG & PTCA \\
\hline \multirow[t]{4}{*}{2009} & 4 & 52 & 35 & 67 & 42 & 30 & Ant 62 & A 6 & 58 & 33 & 91 & 16 \\
\hline & & & & & & & Inf 29 & В 26 & & & & \\
\hline & & & & & & & & C 35 & & & & \\
\hline & & & & & & & & D 23 & & & & \\
\hline \multirow[t]{4}{*}{2010} & 5 & 63 & 40 & 82 & 55 & 35 & Ant 60 & A 8 & 72 & 36 & 108 & 52 \\
\hline & & & & & & & $\operatorname{lnf} 48$ & B 32 & & & & \\
\hline & & & & & & & & C 41 & & & & \\
\hline & & & & & & & & D 27 & & & & \\
\hline \multirow[t]{4}{*}{2011} & 5 & 52 & 33 & 71 & 48 & 40 & Ant 57 & A 5 & 63 & 27 & 90 & 30 \\
\hline & & & & & & & $\operatorname{lnf} 31$ & B 25 & & & & \\
\hline & & & & & & & Post 2 & C 38 & & & & \\
\hline & & & & & & & & D 22 & & & & \\
\hline \multirow[t]{4}{*}{2012} & 15 & 60 & 27 & 80 & 52 & 58 & Ant 70 & A 6 & 81 & 21 & 102 & 39 \\
\hline & & & & & & & Inf 32 & B 32 & & & & \\
\hline & & & & & & & & C 44 & & & & \\
\hline & & & & & & & & D 20 & & & & \\
\hline \multirow[t]{4}{*}{2013} & 7 & 43 & 10 & 43 & 31 & 32 & Ant 40 & A 3 & 53 & 7 & 60 & 35 \\
\hline & & & & & & & $\operatorname{lnf} 20$ & В 27 & & & & \\
\hline & & & & & & & & C 25 & & & & \\
\hline & & & & & & & & D 5 & & & & \\
\hline Total & 36 & 269 & 145 & 343 & 228 & 195 & & & & & 451 & 172 \\
\hline
\end{tabular}

ACS acute coronary syndrome, STEMI ST elevation myocardial infarction, NSTEM non ST elevation myocardial infarction, UA unstable angina, HTN hypertension, DM diabetes mellitus, SM smoking, REGION myocardial territory, Ant-Anterior region, Inf- Inferior region, Post Posterior/lateral region, M male, $\mathrm{F}$ female, CAG coronary angiogram, PTCA percutaneous transluminal coronary angioplasty.

Table 1: Data Master Chart for ACS in a Private Tertiary Hospital.

\section{Acute coronary syndrome}

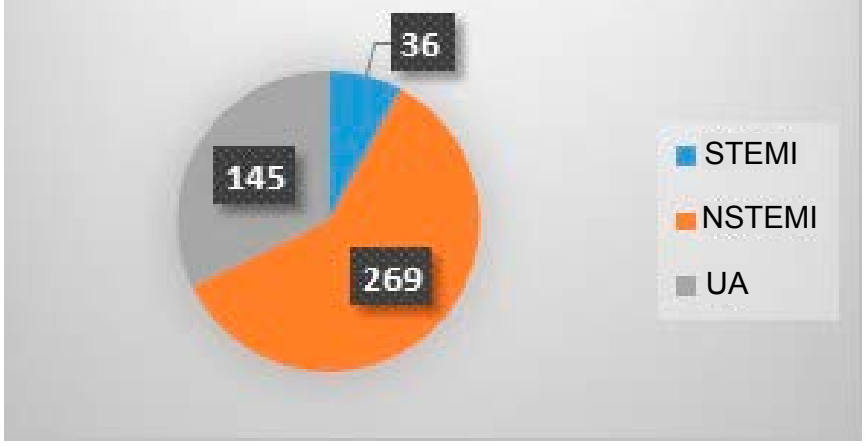

Figure 1: Distribution of ACS.

a continuing burden of cardiovascular morbidity and mortality. Improving the lifestyles of patients in the region will be crucial for improving long-term outcomes, although cultural and other barriers will need to be overcome. Appropriate vision and emphasis is required for the management of cardiovascular risk factors and cardiovascular disease in this part of the world. The patient profile and characteristics including the risk profile helps us to understand the demographic variation and prevalence in our mix of multi ethnic, migrant and expat population utilizing the private healthcare sector services. 
Citation: Barman M, Djamel B (2014) Clinical Spectrum of Acute Coronary Syndromes in Qatar. J Cardiovasc Dis Diagn 2: 149. doi:10.4172/2329-

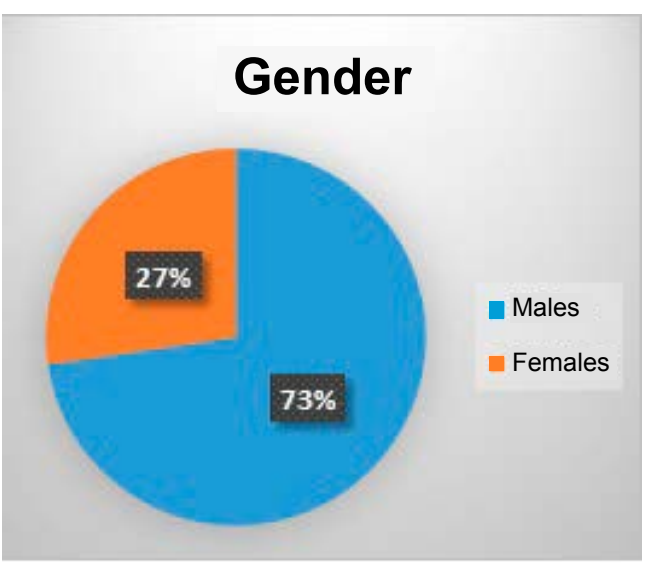

Figure 2: Gender distribution of ACS.

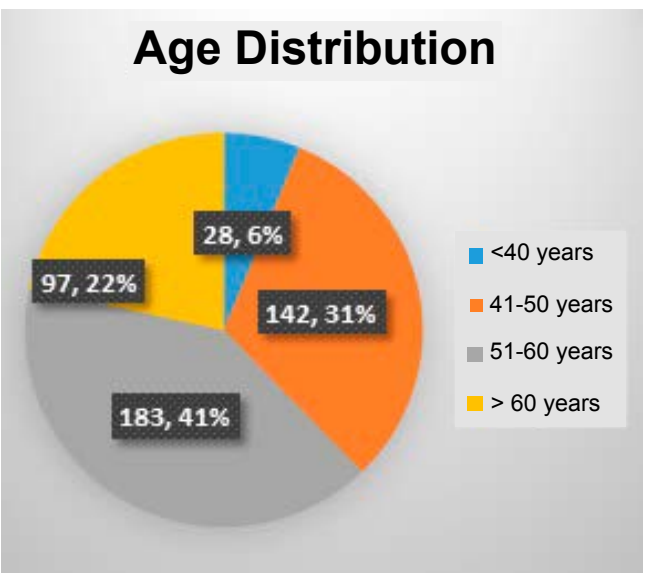

Figure 3: Age distribution of ACS.

\section{RISK FACTORS IN 450 PATIENTS}
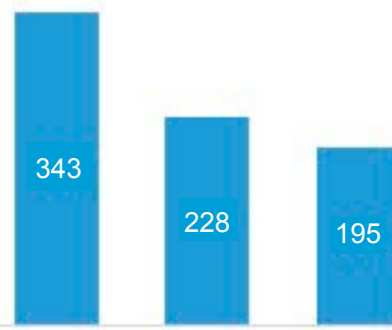

HTN

DIABETES SMOKING

Figure 4: Risk factors in all patients. Overlap exists.

\section{References}

1. Rosamond W, Flegal K, Furie K, Go A, Greenlund K, et al. (2008) Heart disease and stroke statistics--2008 update: a report from the American Heart Association Statistics Committee and Stroke Statistics Subcommittee. Circulation 117: e25-146.

2. Lloyd-Jones D, Adams RJ, Brown TM, Carnethon M, Dai S, et al. (2010) Executive summary: heart disease and stroke statistics--2010 update: a report from the American Heart Association. Circulation 121: 948-954.

3. Lloyd-Jones DM1, Larson MG, Beiser A, Levy D (1999) Lifetime risk of developing coronary heart disease. Lancet 353: 89-92.

4. Lopez AD, Mathers CD, Ezzati M, Jamison DT, Murray CJ, et al. (2006) Global and regional burden of disease and risk factors, 2001: systematic analysis of population health data. Lancet 367:1747-1757.

5. Allender S, Scarborough P, O'Flaherty M, Capewell S (2008) Patterns of coronary heart disease mortality over the 20th century in England and Wales: Possible plateaus in the rate of decline. BMC Public Health 8: 148.

6. Almahmeed W, Arnaout MS, Chettaoui R, Ibrahim M, Kurdi MI, et al. (2012) Coronary artery disease in Africa and the Middle East. TherClin Risk Manag 8: $65-72$.

7. Fox KA (2004) Management of acute coronary syndromes: an update. Heart 90: 698-706.

8. White HD, Barbash GI, Califf RM, Simes RJ, Granger CB, et al. (1996) Age and outcome with contemporary thrombolytic therapy. Results from the GUSTO-I trial. Global Utilization of Streptokinase and TPA for Occluded coronary arteries trial. Circulation 94: 1826-1833.

9. Fassa AA, Urban P, Radovanovic D, Duvoisin N, Gaspoz JM, et al. (2005) Trends in reperfusion therapy of ST segment elevation myocardial infarction in Switzerland: six year results from a nationwide registry. Heart 91: 882-888.

10. Patel MR, Chen AY, Roe MT, Ohman EM, Newby LK, et al. (2007) A comparison of acute coronary syndrome care at academic and nonacademic hospitals. Am J Med 120: 40-46.

11. Watkins S, Thiemann D, Coresh J, Powe N, Folsom AR, et al. (2005) Fourteenyear (1987 to 2000) trends in the attack rates of, therapy for, and mortality from non-ST-elevation acute coronary syndromes in four United States communities. Am J Cardiol 96: 1349-1355.

12. de Winter RJ, Windhausen F, Cornel JH, Dunselman $\mathrm{PH}$, Janus $\mathrm{CL}$, et al. (2005) Invasive versus Conservative Treatment in Unstable Coronary Syndromes (ICTUS) Investigators. Early invasive versus selectively invasive management for acute coronary syndromes. N Engl J Med 353: 1095-104.

13. RavinderMamtani. Preventing Heart Disease-Ignoring lifestyle choices is no longer an option. 